\title{
Monthly averaged-hourly solar diffuse radiation model for the UK
}

\author{
T. Muneer ${ }^{1}$, S. Etxebarria ${ }^{2}$, E.J. Gago ${ }^{2 *}$ \\ ${ }^{1}$ Edinburgh Napier University, Edinburgh, UK. Email: t.muneer@napier.ac.uk. \\ ${ }^{2}$ University of Granada, Spain. Email: ejadraque@ugr.es.
}

\begin{abstract}
Monthly-averaged daily global irradiation data are now easily available from NASA website. Using established models it is then possible to decompose the daily - to averaged-hourly global irradiation. The missing link so far has been hourly averaged diffuse irradiation.

In this article data was pooled from $10 \mathrm{UK}$ locations to obtain a regression model to complete the above missing link.

It was presently shown that the averaged - data regressions are distinctly different from previously available hour-by-hour regressions.
\end{abstract}

\section{Keywords}

Solar radiation, averaged-hourly diffuse fraction, clearness index, solar diffuse radiation model

\section{Introduction}

Solar radiation data are essential for the design of building services. These data are needed for obtaining solar energy transmission through glazing and also through opaque fabric such as walls and roof.

In response to the above demand posed by industry, CIBSE provides, and is in the process of extending the work related to production of computed data sets of:

a) Hourly time series of global and diffuse illuminance with the view to obtain frequency of any given level of illuminance

b) Sol-air temperature tables for horizontal and vertical surfaces. These are produced for days that belong to $97.5^{\text {th }}$ percentile when daily irradiation totals are arranged in an ascending order.

c) Monthly-average irradiation for horizontal, vertical and sloped surfaces.

In the preparation of successive editions of CIBSE Guides A [1, 2, 3, 4, 5, 6], Guide J [7] and weather data sets a long-term series of hourly global and diffuse irradiation were required. Not always and also not for all locations (countries which cannot afford the measurement equipment and techniques involved) are measurements of the latter component available though. 
Furthermore, as of year 2000, the UK Meteorological Office has stopped recording diffuse irradiation at all but two locations - Camborne $(50.21 \mathrm{~N})$ and Lerwick $(60.15 \mathrm{~N})$. Therefore, for all of the other major and minor conurbations in the UK the latter component has to be estimated from models that are based on historical records.

The new CIBSE Guide A, to be published in the year 2014, will contain solar radiation tables for 14 UK locations. The above tables will contain information on global and diffuse illuminance, irradiation totals for surfaces of various aspects and slopes, and sol-air temperatures for walls and roof. To produce these tables it is necessary to obtain horizontal-diffuse irradiation, provided global energy data are available. For the above-mentioned 14 locations within the UK it is not always possible to acquire measured diffuse irradiation data as these are seldom available. Hence, it is necessary to develop a mathematical model, built from measured data that is available for some of the above locations.

Another constraint in the present CIBSE Guide A production was that in view of costs, only averagedhourly data were provided by the UK Meteorological Office. The models that were previously developed [10] were not for averaged-data. Rather, they were for use for hour-by-hour records. Hence the previous work [10] was found to be redundant for the present production of CIBSE Guide A.

This article detailed reviews the prior work that has been undertaken in this respect and then progresses to report newer, averaged-hourly diffuse irradiation models. The use and justification of such models is also presented.

\section{The need for diffuse irradiation models}

In addition to their use in other disciplines such as agriculture, there are a large number of engineering applications where, beam and diffuse irradiation hourly or sub-hourly are required. The two components are used to estimate, among other things, slope radiation. A brief list of those applications may be drawn thus:

- Solar transmission through building fenestration

- Daylight transmission through building fenestration

- Sol-air temperature estimation for opaque building fabric

- Solar water heating design and product assessment

- Solar PV design and product assessment

For above mentioned items (a) and (b), in Section 1, an hour-by-hour diffuse irradiation model is required and previous research has made such work available for the UK $[8,9]$

In Section 3 some of the above work is reviewed.

For generation of tables related to item (c) in Section 1, new work had to be undertaken to develop monthly-averaged hourly regressions and that is the main subject of this article. 
A typical scatter plot for diffuse ratio (ratio of hourly diffuse - to global irradiation) - clearness index (ratio of global - to extraterrestrial irradiation) relationship is shown in Figure 1. The diffuse ratio is represented by $\mathrm{k}$ and the clearness index by $\mathrm{kt}$.

\section{Insert Figure 1}

This plot, obtained from hour-by-hour data provided by the UK-Meteorological Office for the period 1981-1983 displays a convex shape. The regressed curve reported by Muneer and Saluja [10] is:

$$
\frac{I_{D}}{I_{G}}=k=a_{0}+a_{1} k_{t}+a_{2} k_{t}^{2}+a_{3} k_{t}^{3} ; k_{t}>0.2
$$

Values of the "a" coefficients are different for each location (Easthampstead, Aberporth, Aldergrove, Eskdalemuir, Lerwick, United Kingdom).

Figures $2 \mathrm{a}$ and $2 \mathrm{~b}$ respectively show the regressed curves for locations in UK and other countries. Three points are worth mentioning:

i. For all locations the $\mathrm{k}-\mathrm{k}_{\mathrm{t}}$ relationship displays a convex profile, and

ii. For the UK as a whole, it is possible to build a single curvilinear relationship between $\mathrm{k}$ and $\mathrm{k}$, however,

iii. A single curve cannot be constructed to include world-wide locations

\section{Insert Figures $2 \mathrm{a}$ and $2 \mathrm{~b}$}

In the following section 4 an attempt shall be made on developing $\bar{k}-\overline{k_{t}}$ relationship based on monthlyaveraged hourly data. A justification shall also be stated for such work.

\section{Previous work}

As mentioned in Section 1 this work attempts to present a new model that relates averaged-diffuse irradiation to its global counterpart. All previous work has been related to regressions that involve hourby-hour energy quantities. In the following paragraphs a brief review of the older work is carried out as the basic mathematical formulation is unchanged, i.e. diffuse ratio is regressed against clearness index.

Liu and Jordan [11] were pioneers in correlating the relationship between diffuse and global radiation on a horizontal surface, however, the original correlation of Liu and Jordan was developed for daily-not hourly values.

Very many research teams have since developed hourly regressions that primarily relate $k$, the diffuse ratio (diffuse to global irradiation) to $\mathrm{k}_{\mathrm{t}}$, the clearness index (global to extra-terrestrial irradiation ratio) (see Table 1). 
Orgill and Hollands [12], from information gathered in Toronto, Canada, proposed the a linear model for the diffuse ratio $(k)$ according to the hourly clearness index $\left(\mathrm{k}_{\mathrm{t}}\right)$. This study was based upon 4 years of data for Toronto in Canada. The diffuse radiation was measured with a shadow-band Pyranometer.

Erbs et al. [13] followed the procedure of Orgill and Hollands to develop a correlation for the U.S. locations (Fort Hood, Tex.; Maynard, Mass.; Raleigh, N.C.; Livermore, Calif.) with a latitude range of $31-42^{\circ} \mathrm{N}$. Pyroheliometric data was used by them in which diffuse radiation was obtained via subtraction of direct radiation from global, measured with a pyranometer.

Reindl et al. [15] using data respectively from five European and North American locations analyzed the influence of commonly measured climatic variables on the diffuse fraction and correlating the significant variables to reduce the standard error of Liu and Jordan [11] type models. The new correlation reduced the composite residual sum of squares by $14.4 \%$ when compared to a $\mathrm{k}$, correlation derived from the same data set. The reduced form of the correlation reduced the composite residual sum squares by $9.2 \%$. When an independent data set is used, the new correlation reduced the residual sum of squares by $26 \%$ compared to the Erbs' correlation.

Hawlader [14] using data from a tropical site in Singapore derived the second-order polynomial correlation. Equations were developed to estimate diffuse fraction of the hourly, daily and monthly global insolation on a horizontal surface. The hourly correlation equations showed a fairly similar trend to that of Orgill and Hollands [12] and supported your view on latitude dependence.

Chandrasekaran and Kumar [16] using data from a tropical environment in Madras, India, derived a fourth-order polynomial correlation. These correlations were compared to those developed by Orgill and Hollands [12], Erbs et al. [13], and Reindl et al. [15], which were obtained from data of temperate locations. The comparison was performed in terms of standard deviation and relative standard deviation. The results indicated that the proposed correlations are better. The best tits were obtained when the seasonal effects were taken into account. It is also showed that the hourly diffuse fraction is larger at a tropical location at higher hourly clearness indices.

Boland et al. [17] with data from a station in Victoria, Australia. A significant finding was that the same model can be used for both 15 minute and hourly data.

Miguel et al. [18] used an assembled data set from several countries in the North Mediterranean Belt area, and yielded a third-order polynomial for hourly diffuse fraction correlations. The performed data analysis showed that under overcast-sky conditions (low values of k) a large portion of the incoming radiation is scattered by the clouds in the atmosphere resulting in a large diffuse fraction. The significance of low solar altitudes in the diffuse solar fraction increases under clear sky (high values of $k$ ). The Liu and Jordan [11] model was recommended to calculate hourly diffuse from daily diffuse values since it reproduces the observed data series extremely well.

Oliveira et al. [19] using data from a tropical Sao Paolo site, Brazil, proposed a fourth order polynomial correlation. One of the major conclusion was that the overall characteristics of the diffuse-fraction 
correlation curves and their seasonal variations are similar to other places with equivalent latitude for hourly, daily and monthly values [13].

Karatasou et al. [20] based on data from Athens, Greece, proposed a third-order polynomial correlation. The goal of this study was to reduce the standard error of the current Liu and Jordan [11] type correlations, when used for Athens location.

Soares et al. [21] basing on the same data set as [19], established a synthetic fourth-order polynomial correlation by means of a neural network technique. It was found that the inclusion of the atmospheric long-wave radiation as input improves the neural-network performance. On the other hand traditional meteorological parameters, like air temperature and atmospheric pressure, are not as important as long-wave radiation which acts as a surrogate for cloud-cover information on the regional scale. An objective evaluation showed that the diffuse solar radiation is better reproduced by neural network synthetic series than by a correlation model.

\section{Insert Table 1}

\section{Monthly-averaged, $\bar{k}-\overline{k_{t}}$ relationship}

The previous section reviewed the $\mathrm{k}-\mathrm{k}_{\mathrm{t}}$ relationship that was based on hour-by-hour data. It was also shown that during the past forty years such regressions have been presented for very many regions of the world. It is however, interesting to note that there is a dearth of such knowledge for diffuse ratio clearness index regressions that are based on averaged data.

The need to produce $\overline{\mathrm{k}}-\overline{\mathrm{k}_{\mathrm{t}}}$ relationship presently stemmed from three factors:

i. In the production of the latest version of CIBSE Guide A (2014), in view of the prohibitive cost of measured data only monthly-averaged hourly records were obtained by the CIBSE Solar Data Task Group. These data, obtained for 14 UK locations, are of very high quality as shall be demonstrated in the following section.

ii. As mentioned earlier that, as of year 2000, all Meteorological Office stations, with the exception of Camborne and Lerwick, have ceased to record diffuse component.

iii. Through the work of NASA [22] it is now possible to obtain daily-averaged irradiation data for virtually any location in the world. A sample table of climatic data for Easthampstead (Bracknell) is provided in Table 2. This information was downloaded from the above-mentioned NASA website. Note that the NASA reported irradiation data were compared against averaged measured data for the period 1981-1983 (three complete years) (see Figure 3). The statistics within the latter figure shows that there is a close concordance between the satellite-based NASA irradiation-and the UK Meteorological Office measured data set. 
It is therefore possible to construct a three-step computational chain that links with the NASA data that now exists in public domain to obtain all manner of solar energy calculations that require hourly horizontal and slope, global and diffuse irradiation. Figure 4 shows the above mentioned computational chain.

\section{Insert Figure 4}

\section{Analysis and discussion}

The data used for this study were obtained from UK Meteorological Office. Ten locations were chosen which are detailed in Table 3 and Figure 5. Data consisted of hourly global and diffuse irradiation values for several years for each location, covering the most of the range of latitude for the country. The location names have been arranged in increasing order of latitude.

Insert Table 3

Insert Figure 5

Monthly-averaged hourly values were calculated for the global and diffuse radiation considering the data period for each location.

For each of them, the diffuse ratio $(k)$ and the clearness index $\left(\mathrm{k}_{\mathrm{t}}\right)$ for every hour in each month were calculated. The following conditions were used in each case to remove erroneous recorded data.

$k_{T}=\frac{I_{G}}{I_{E}} \rightarrow I_{G}<I_{E}$

$k=\frac{I_{D}}{I_{G}} \rightarrow I_{D} \leq I_{G}$

The monthly-averaged clearness index was then regressed against the monthly-averaged diffuse ratio for each location. Figure 6 shows one such scatter plot for Bracknell. Furthermore, for each increment at bandwidth of clearness index of 0.05 width, the corresponding values of diffuse ratio shown in Figure 7 were again averaged.

\section{Insert Figures 6 and 7}

The data from all ten locations were found to have a similar degree of scatter as depicted in Figure 5. Figures 8 and 9 respectively display the all-location scatter plot and bin-wise averaged plot.

\section{Insert Figures 8 and 9}

In solar radiation studies, it is common to encounter data that lie unusually far from the bulk of the data population. These data are called outliers and in literature there are standard statistical tests to ascertain if those data are indeed outliers [25].

In this study though, none of the data were found to be outliers. 
A point worth mentioning here is that in almost all cases of the data from 10 locations that is under examination, there is an increasing trend of diffuse ratio for the top end of clearness index. This is a well-known phenomenon that is associated with simultaneous occurrence of two astronomical I weather-related conditions:

- Low solar altitude angle, and

- Sun shining strongly through a broken cloud

The result is that a high clearness index is obtained from a high beam irradiation augmented with skydiffuse and cloud-reflected radiation as is also a high value of diffuse ratio. The above phenomenon is depicted in Figure 10.

\section{Insert Figure 10}

Table 4 sheds further light on those points that belong to the class of data under discussion.

\section{Insert Table 4}

A single regression curve for UK was obtained by pooling all data include in Figure 9. That regression model is given in the following equation:

$$
\bar{k}=0.89 \overline{k_{t}^{2}}-1.185 \overline{k_{t}}+0.95
$$

\section{Conclusions}

It was presently shown that monthly-averaged hourly data for solar radiation are much more economical to obtain than hour-by-hour records. Furthermore, through NASA website one may freely obtain daily solar data which may easily be decomposed into hourly global irradiation time-series. The missing link so far has been averaged-hourly diffuse irradiation.

This work fills that gap. A single regression equation has presently been obtained for the UK as a whole. Application of this equation has enabled production of Vertical Surface irradiation data for 24 key UK locations that form an important part of CIBSE Guide A (2014) [6].

\section{Acknowledgement}

\section{References}

1. CIBSE/Met. Office Hourly Weather Data. October 2005. WCD03-SET (issue 2). Design Summer Year/Test Reference Year.

2. CIBSE/Met. Office Hourly Weather Data. 2002.

3. CIBSE Future Weather Years. July 2009.

4. CIBSE Guide A (1999). Chartered Institution of Building Services Engineers, London.

5. CIBSE Guide A (2006). Chartered Institution of Building Services Engineers, London.

6. CIBSE Guide A (2014). Chartered Institution of Building Services Engineers, London. 
7. CIBSE Guide J (2000). Chartered Institution of Building Services Engineers, London.

8. Page J. K. (1961). The estimation of monthly mean values of daily total shortwave radiation on vertical and inclined surfaces from sunshine records for latitudes 40"N-40"s. Proc. UN Conf. on New Sources of Energy, 21-31 August 1961, Rome, Italy. United Nations, Paper No 3515198.

9. http://www.helioclim.org/esra/.

10. T. Muneer and G.S. Saluja. Correlation between hourly diffuse and global solar irradiation for the UK. Building Services Engineering Research \& Technology. Vol. 7. No. 1. 1996.

11. Y. H. Liu and R. C. Jordan, The interrelationship and characteristic distribution of direct, diffuse and total solar radiation. Solar Energy 4, 1-19 (1960).

12. Orgill JF, Hollands KGT. Correlation equation for hourly diffuse radiation on a horizontal surface. Sol Energy 1977;19:357-9.

13. Erbs DG, Klein SA, Duffie JA. Estimation of the diffuse radiation fraction for hourly, daily and monthly average global radiation. Sol Energy 1982;28:293-302.

14. Hawlader MNA. Diffuse, global and extraterrestrial solar radiation for Singapore. Int J Ambient Energy 1984;5:31-8.

15. Reindl DT, Beckman WA, Duffie JA. Diffuse fraction correlations. Sol Energy 1990;45:1-7.

16. Chandrasekaran J, Kumar S. Hourly diffuse fraction correlation at a tropical location. Sol Energy 1994;53:505-10.

17. Boland J, Scott L, Luther M. Modeling the diffuse fraction of global solar radiation on a horizontal surface. Environmetrics 2001;12:103-16.

18. Miguel A, Bilbao J, Aguiar R, Kambezidis H, Negro E. Diffuse solar irradiation model evaluation in the north Mediterranean belt area. Sol Energy 2001;70:143-53.

19. Oliveira AP, Escobedo JF, Machado AJ, Soares J. Correlation models of diffuse solar radiation applied to the city of Sao Paulo, Brazil. Appl Energy 2002;71:59-73.

20. Karatasou S, Santamouris M, Geros V. Analysis of experimental data on diffuse solar radiation in Athens, Greece, for building applications. Int J Sustain Energy 2003;23(1-2):1-11.

21. Soares J, Oliveira AP, Boznar MZ, Mlakar P, Escobedo JF, Machado AJ. Modeling hourly diffuse solar radiation in the city of Sao Paulo using a neural-network technique. Appl Energy 2004;79:201-1

22. http://eosweb.larc.nasa.gov/cgi-bin/sse/retscreen.cgi?email=rets@nrcan.gc.ca.

23. E.J. Gago, S. Etxebarria, Y. Tham, Y. Aldali and T. Muneer. Inter-relationship between meandaily irradiation and temperature, and decomposition models for hourly irradiation and temperature. International Journal of Low-Carbon Technologies 2011, 6, 22-37.

24. Y. Tham, T. Muneer. Sol-air temperature and daylight illuminance profiles for the UKCP09 data sets. Building and Environment 46 (2011) 1243-1250.

25. Muneer T. Solar Radiation and Daylight Models, 2nd edn. Elsevier, 2004. 


\section{LIST OF FIGURES}

Figure 1. Hourly diffuse ratio versus clearness index for the UK

Figure 2a. Average hourly diffuse ratio versus clearness index for 5 locations in the UK

Figure 2b. Average hourly diffuse ratio (y-axis) versus clearness index (x-axis) for 5 world locations

Figure 3. Comparison between NASA reported irradiation data and ground-based averaged measured data for Bracknell

Figure 4. Computational chain

Figure 5. UK map showing the 10 locations that are the basis of present work

Figure 6. Monthly-averaged hourly diffuse ratio (y-axis) versus clearness index (x-axis) for Bracknell

Figure 7. Averaged values of diffuse ratio (y-axis) versus clearness index (x-axis) for Bracknell

Figure 8. Monthly-averaged hourly $\overline{\mathrm{k}}-\overline{\mathrm{k}_{\mathrm{t}}}$ plot for the UK (locations arranged in an increasing order of latitude). Note: $\bar{k}$ (y-axis), $\bar{k}_{t}$ (x-axis)

Figure 9. Averaged values of diffuse ratio for the UK (locations arranged in an increasing order of latitude). Note: $\bar{k}$ (y-axis), $\bar{k}_{t}$ (x-axis)

Figure 10. Demonstration of atmospheric condition when diffuse irradiation is enhanced under a partly clouded sky with a low solar altitude 


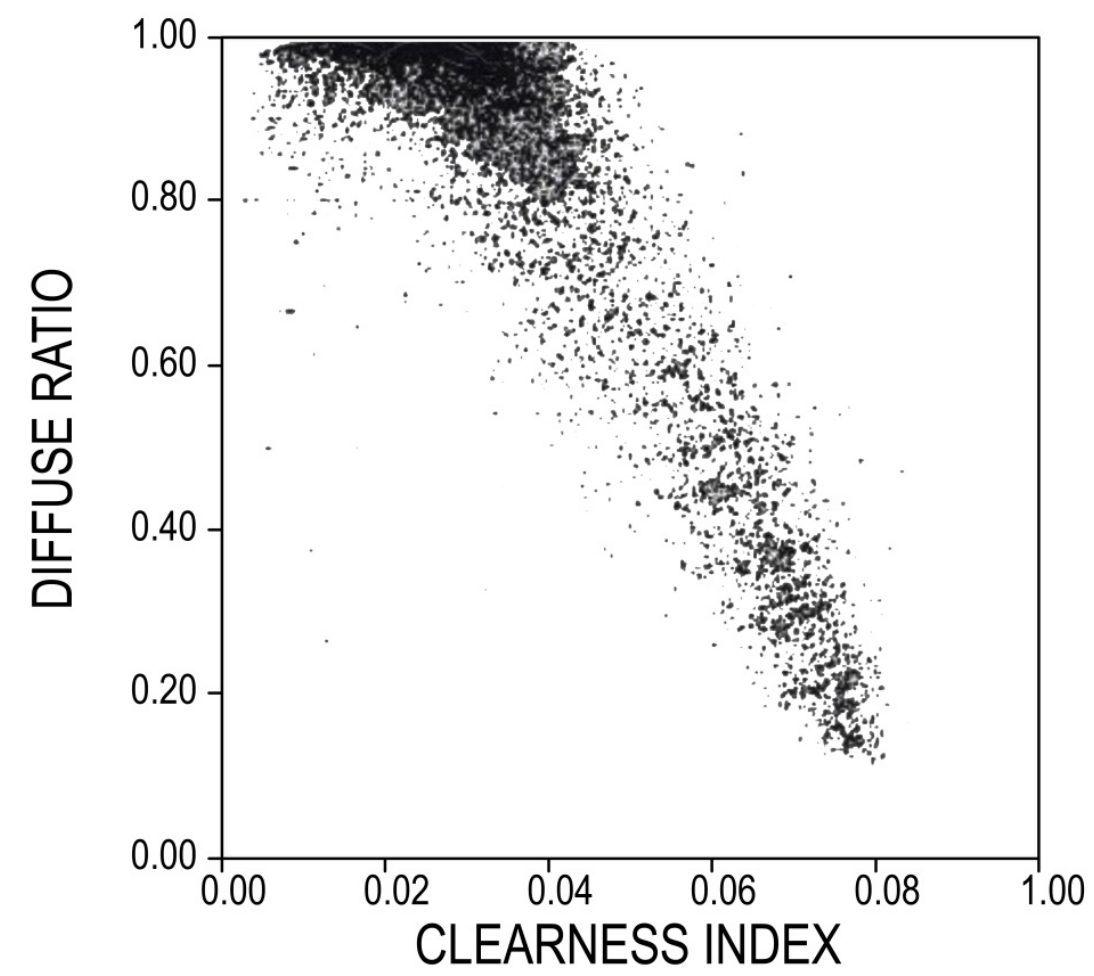

Figure 1. Hourly diffuse ratio versus clearness index for the UK

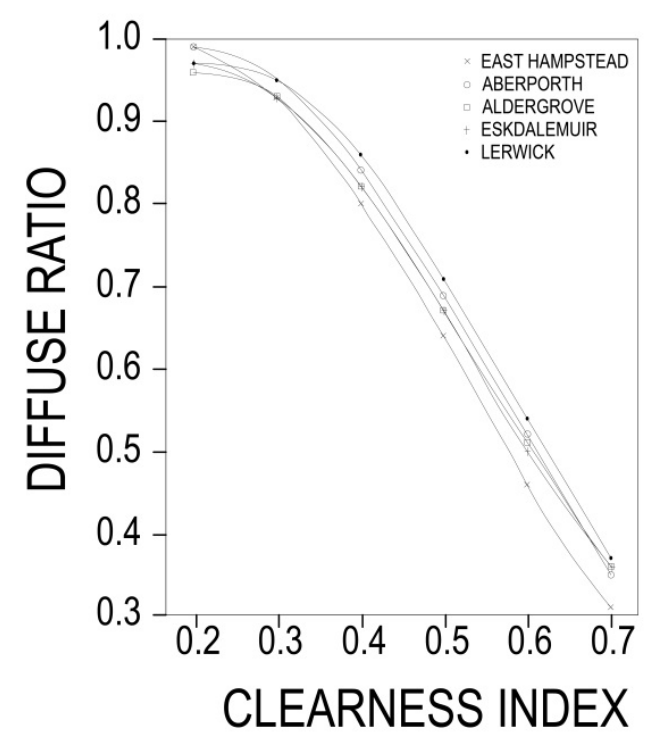

Figure 2a. Average hourly diffuse ratio versus clearness index for 5 locations in the UK 


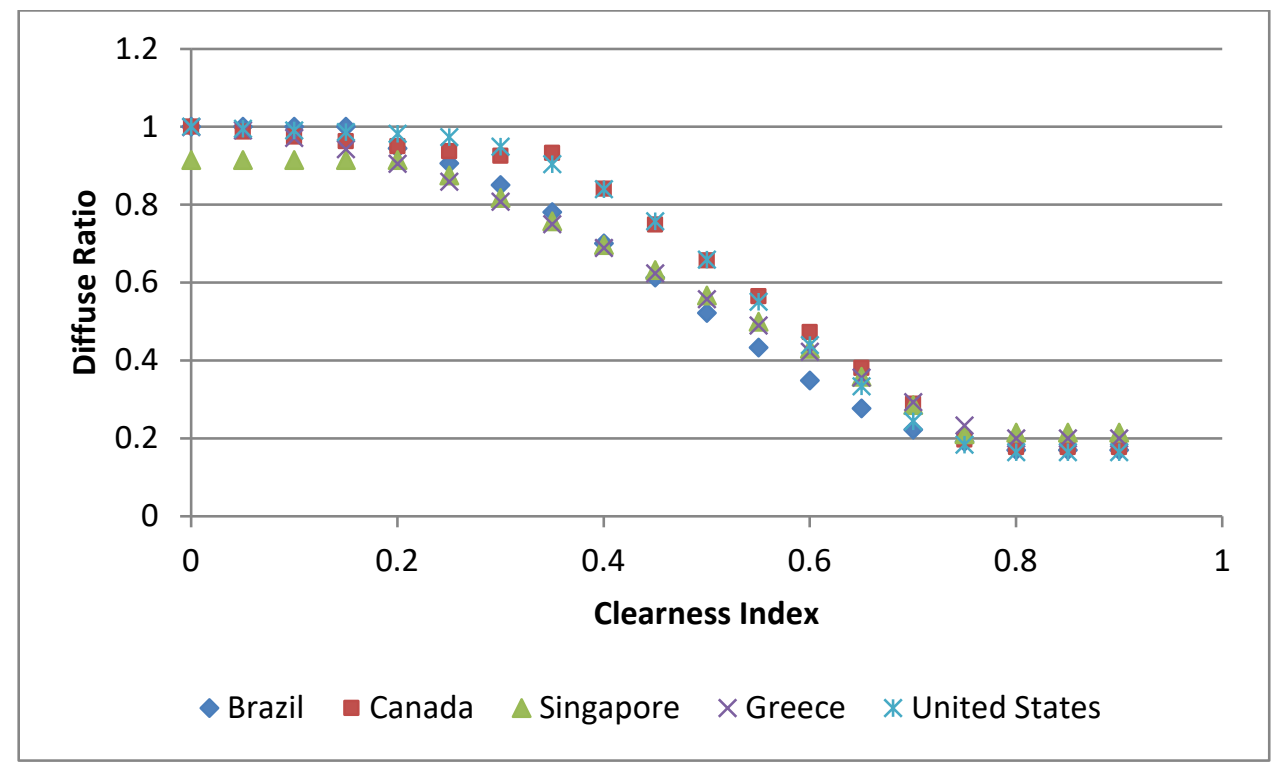

Figure $\mathbf{2 b}$. Average hourly diffuse ratio (y-axis) versus clearness index (x-axis) for 5 world locations

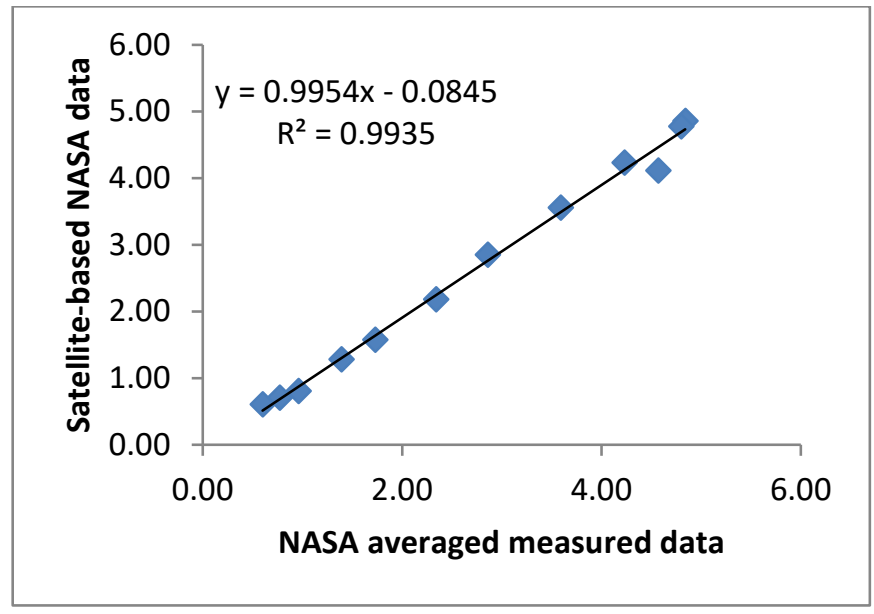

Figure 3. Comparison between NASA reported irradiation data and ground-based averaged measured data for Bracknell 


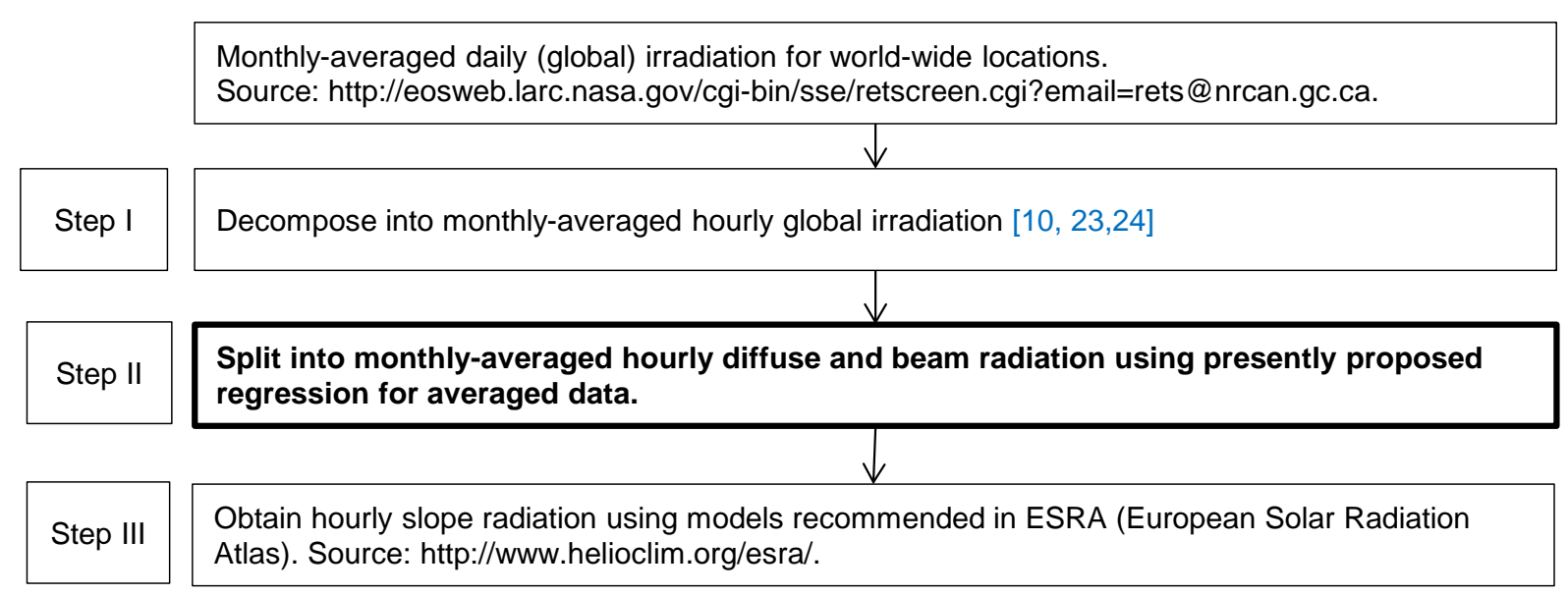

Figure 4. Computational chain 


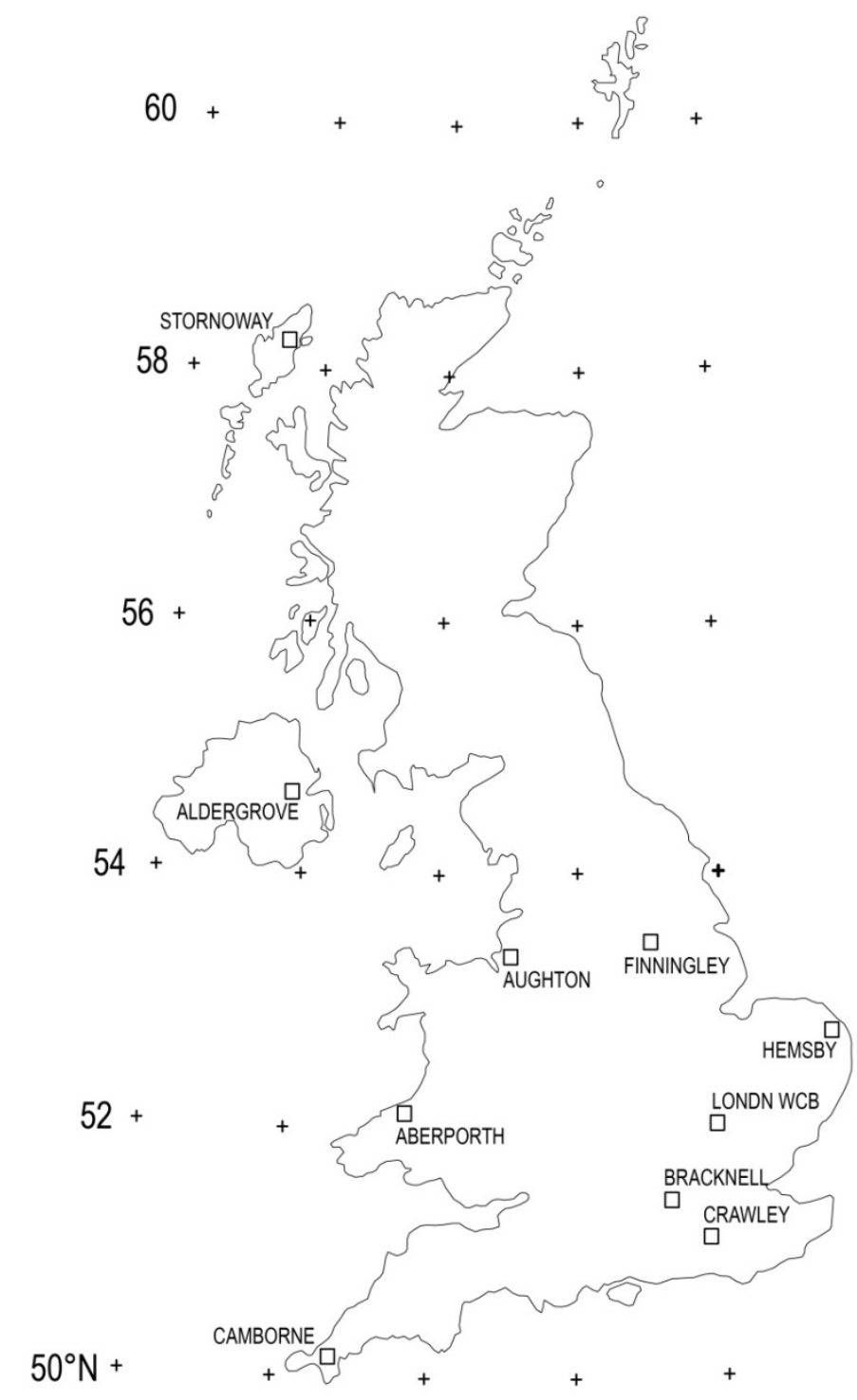

Figure 5. UK map showing the 10 locations that are the basis of present work 


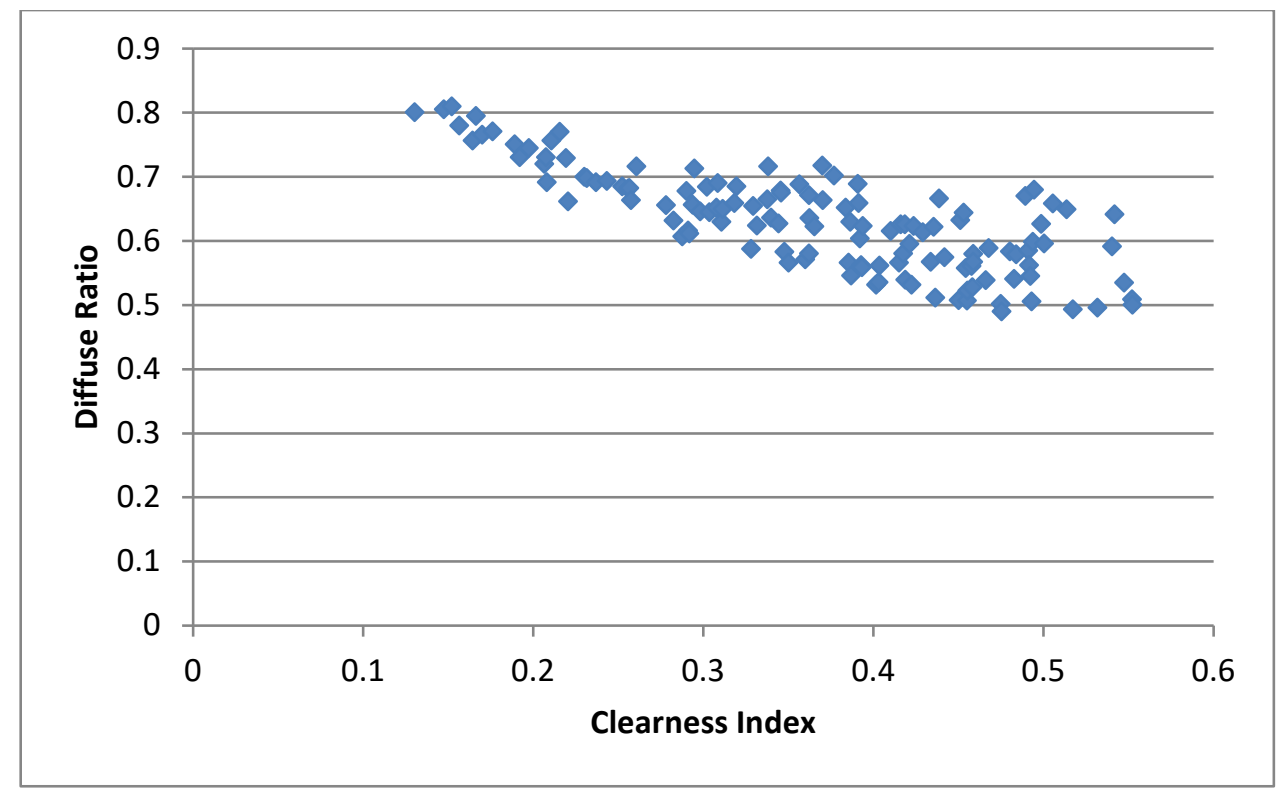

Figure 6. Monthly-averaged hourly diffuse ratio (y-axis) versus clearness index (x-axis) for Bracknell

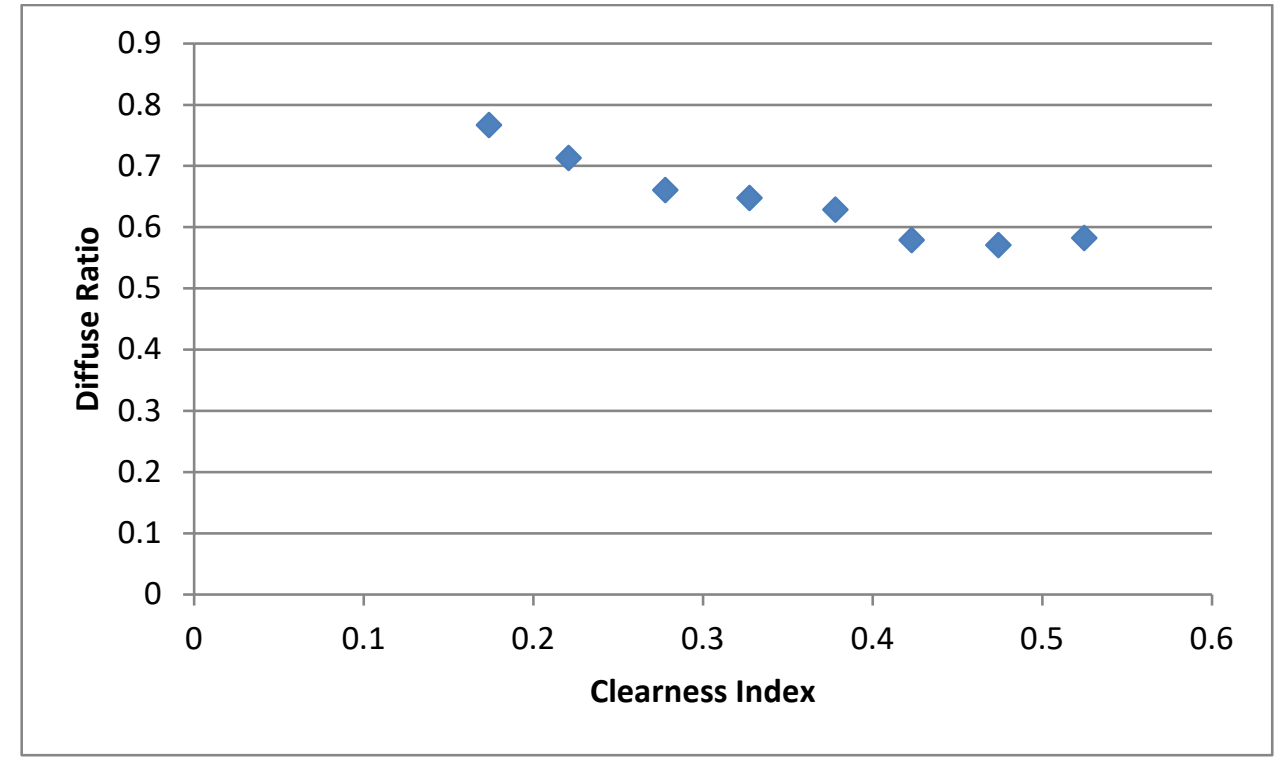

Figure 7. Averaged values of diffuse ratio (y-axis) versus clearness index (x-axis) for Bracknell 


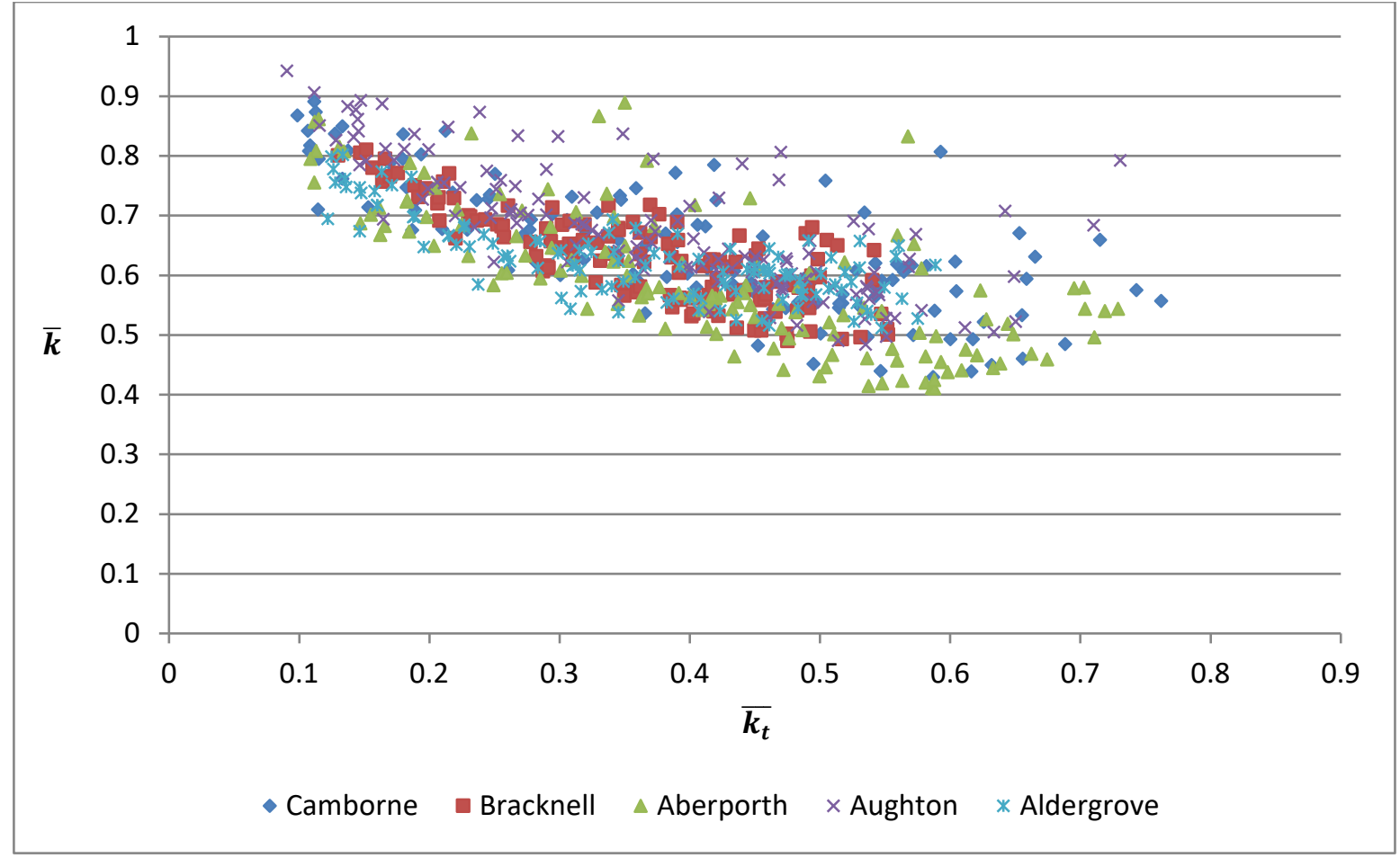

Figure 8. Monthly-averaged hourly $\overline{\mathrm{k}}-\overline{\mathrm{k}}_{\mathrm{t}}$ plot for the UK (locations arranged in an increasing order of latitude). Note: $\bar{k}$ (y-axis), $\bar{k}_{t}$ (x-axis) 


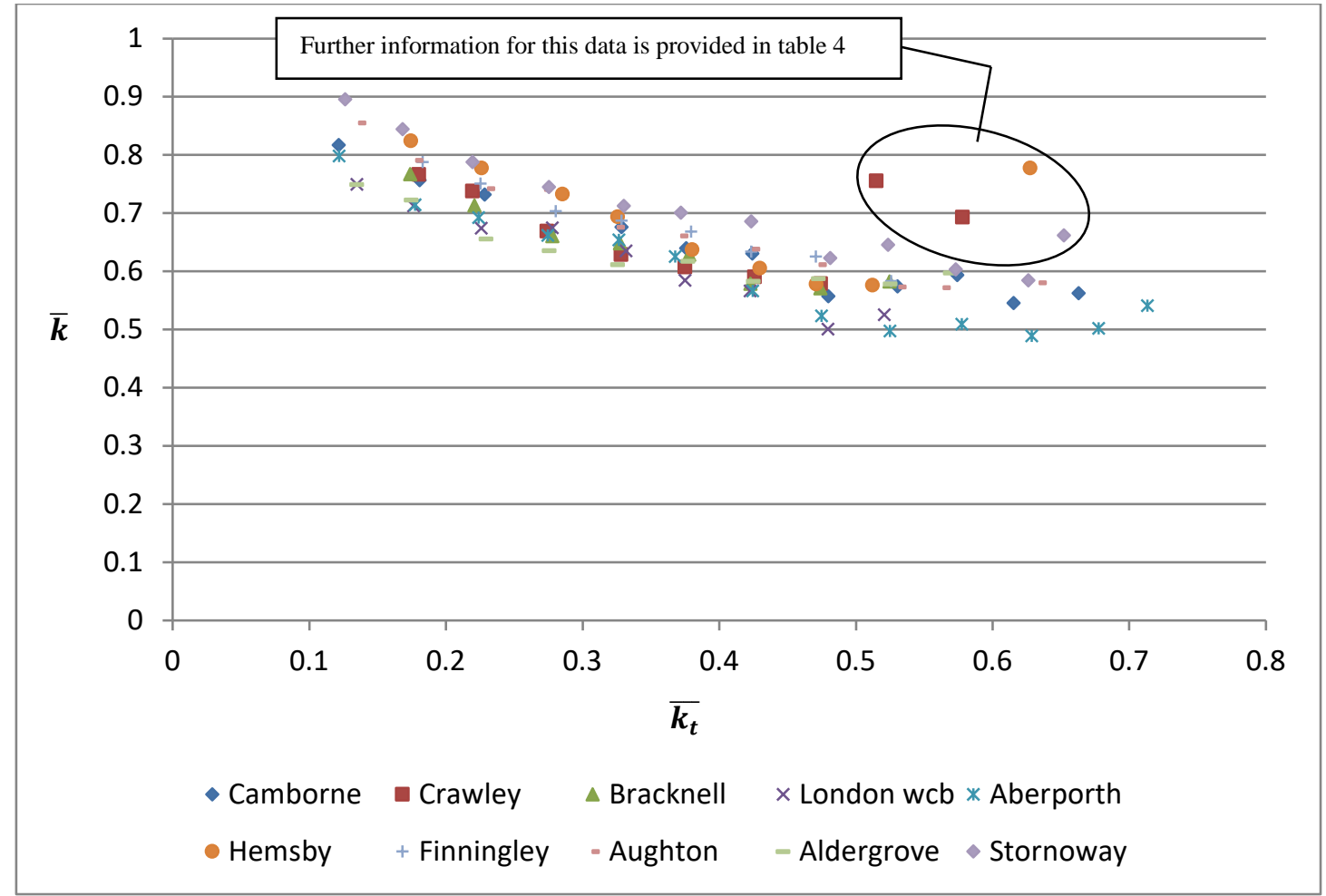

Figure 9. Averaged values of diffuse ratio for the UK (locations arranged in an increasing order of latitude). Note: $\bar{k}$ (y-axis), $\overline{k_{t}}$ (x-axis) 

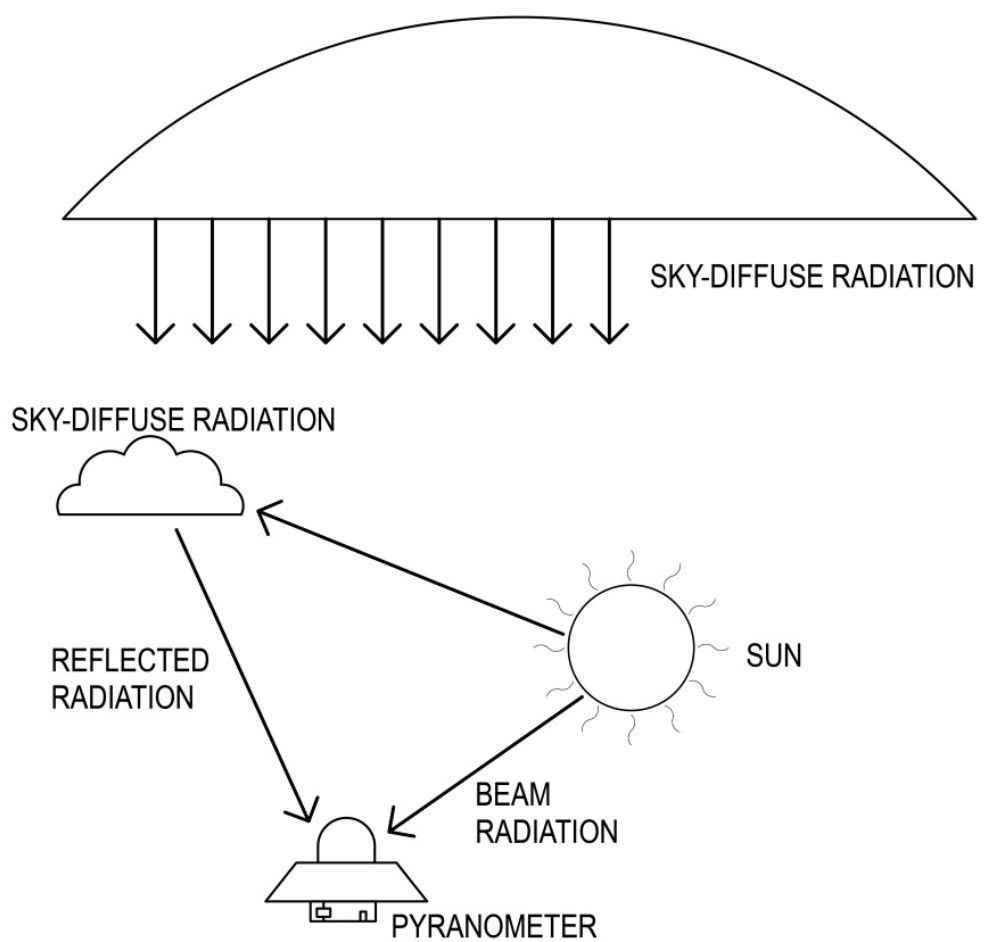

Figure 10. Demonstration of atmospheric condition when diffuse irradiation is enhanced under a partly clouded sky with a low solar altitude 


\section{LIST OF TABLES}

Table 1. Correlations for $\mathrm{k}$ (ratio of hourly diffuse - to global irradiation) and $\mathrm{k}_{\mathrm{t}}$ (ratio of global - to extraterrestrial irradiation).

Table 2. Climatic data for Easthampstead (Bracknell) with the NASA reported irradiation data and averaged measured data for the period 1981-1983.

Table 3. The 10 locations that were presently investigated.

Table 4. High clearness index data. 
Table 1. Correlations for $\mathrm{k}$ (ratio of hourly diffuse - to global irradiation) and $\mathrm{kt}_{\mathrm{t}}$ (ratio of global - to extraterrestrial irradiation)

\begin{tabular}{|c|c|c|c|}
\hline Investigators & Correlation equation & $\begin{array}{l}\text { Number } \\
\text { of } \\
\text { locations }\end{array}$ & $\begin{array}{l}\text { Amount of data } \\
\text { used } \\
\text { (year) }\end{array}$ \\
\hline Orgill and Hollands [12] & $\begin{array}{l}k=1.0-0.249 k_{t} \text { for } k_{t}<0.35 \\
k=1.157-1.84 k_{t} \text { for } 0.35 \leq k_{t} \leq 0.75 \\
k=0.177 \text { for } k_{t}<0.75\end{array}$ & 1 & 4 \\
\hline Erbs et al. [13] & $\begin{array}{l}k=1.0-0.099 k_{t} \text { for } k_{t}<0.22 \\
k=0.9511-0.160 k_{t}+4.388 k_{t}^{2}-16.638 k_{t}^{3}+12.336 k_{t}^{4} \quad \text { for } 0.22<k_{t} \leq 0.80 \\
k=0.165 \text { for } k_{t}>0.80\end{array}$ & 4 & 2 \\
\hline Reindl et al. [15] & $\begin{array}{l}k=1.02-0.249 k_{t} \text { for } k_{t}<0.3 \\
k=1.45-1.67 k_{t} \text { for } 0.3<k_{t}<0.78 \\
k=0.147 k_{t} \text { for } k_{t} \geq 0.78\end{array}$ & 5 & 2,5 \\
\hline Hawlader [14] & $\begin{array}{l}k=1.135-0.9422 k_{t}-0.3878 k_{t}^{2} \text { for } 0.225<k_{t}<0.775 \\
k=0.915 \text { for } k_{t} \leq 0.225 \\
k=0.215 \text { for } k_{t} \geq 0.775\end{array}$ & 1 & 6 \\
\hline Chandrasekaran and Kumar [16] & $\begin{array}{l}k=0.9686-0.1325 k_{t}-1.4183 k_{t}^{2}+10.1862 k_{t}^{3}+8.3733 k_{t}^{4} \quad \text { for } 0.24<k_{t} \leq 0.80 \\
k=1.0086-0.178 k_{t} \text { for } k_{t} \leq 0.24 \\
k=0.197 \text { for } k_{t}>0.80\end{array}$ & 1 & 5 \\
\hline Boland et al. [17] & $k=1 /\left[1+\exp \left(-5.0033+8.6025 k_{t}\right)\right]$ & 4 & 67 days \\
\hline Miguel et al. [18] & $\begin{array}{l}k=0.724+2.738 k_{t}-8.32 k_{t}^{2}+4.967 k_{t}^{3} \text { for } 0.21<k_{t} \leq 0.76 \\
k=0.995-0.081 k_{t} \text { for } k_{t} \leq 0.21 \\
k=0.18 \text { for } k_{t}>0.76\end{array}$ & 11 & 22 \\
\hline Oliveira et al. [19] & $\begin{array}{l}k=0.97+0.8 k_{t}-3.0 k_{t}^{2}-3.1 k_{t}^{3}+5.2 k_{t}^{4} \text { for } 0.17<k_{t}<0.75 \\
k=1.0 \text { for } k_{t} \leq 0.17 \\
k=0.17 \text { for } k_{t}>0.75\end{array}$ & 1 & 5 \\
\hline Karatasou et al. [20] & $\begin{array}{l}k=0.9995-0.05 k_{t}-2.4156 k_{t}^{2}+1.4926 k_{t}^{3} \text { for } 0<k_{t} \leq 0.78 \\
k=0.20 \text { for } k_{t}>0.78\end{array}$ & 1 & 2 \\
\hline Soares et al. [21] & $\begin{array}{l}k=0.90+1.1 k_{t}-4.5 k_{t}^{2}+0.01 k_{t}^{3}+3.14 k_{t}^{4} \text { for } 0.17<k_{t}<0.75 \\
k=1.0 \text { for } k_{t} \leq 0.17 \\
k=0.17 \text { for } k_{t}>0.75\end{array}$ & 1 & 3 \\
\hline
\end{tabular}


Table 2. Climatic data for Easthampstead (Bracknell) with the NASA reported irradiation data and averaged measured data for the period 1981-1983

\begin{tabular}{|c|c|c|c|c|c|c|c|c|c|}
\hline & Unit & $\begin{array}{c}\text { Climate } \\
\text { data } \\
\text { location }\end{array}$ & & & & & & & \\
\hline Latitude & ${ }^{\circ} \mathrm{N}$ & 51,42 & & & & & & & \\
\hline Longitude & ${ }^{\circ} \mathrm{E}$ & $-0,75$ & & & & & & & \\
\hline Elevation & $\mathrm{m}$ & 58,00 & & & & & & & \\
\hline Heating design temperature & ${ }^{\circ} \mathrm{C}$ & $-1,74$ & & & & & & & \\
\hline Cooling design temperature & ${ }^{\circ} \mathrm{C}$ & 22,96 & & & & & & & \\
\hline Earth temperature amplitude & ${ }^{\circ} \mathrm{C}$ & 14,35 & & & & & & & \\
\hline Frost days at site & day & 37,00 & & & & & & & \\
\hline Month & $\begin{array}{c}\text { Air } \\
\text { temperature }\end{array}$ & $\begin{array}{l}\text { Relative } \\
\text { humidity }\end{array}$ & $\begin{array}{l}\text { Daily solar } \\
\text { radiation - } \\
\text { horizontal }\end{array}$ & $\begin{array}{c}\text { Atmospheric } \\
\text { pressure }\end{array}$ & $\begin{array}{l}\text { Wind } \\
\text { speed }\end{array}$ & $\begin{array}{c}\text { Earth } \\
\text { temperature }\end{array}$ & $\begin{array}{c}\text { Heating } \\
\text { degree- } \\
\text { days }\end{array}$ & $\begin{array}{c}\text { Cooling } \\
\text { degree- } \\
\text { days }\end{array}$ & $\begin{array}{l}\text { Average } \\
\text { measured } \\
\text { radiation }\end{array}$ \\
\hline & ${ }^{\circ} \mathrm{C}$ & $\%$ & $\mathrm{kWh} / \mathrm{m}^{2} /$ day & $\mathrm{kPa}$ & $\mathrm{m} / \mathrm{s}$ & ${ }^{\circ} \mathrm{C}$ & ${ }^{\circ} \mathrm{C}-\mathrm{d}$ & ${ }^{\circ} \mathrm{C}-\mathrm{d}$ & $\mathrm{kWh} / \mathrm{m}^{2} /$ day \\
\hline January & 4,2 & $83,90 \%$ & 0,77 & 100,8 & 6,3 & 3,1 & 426 & 1 & 0,71 \\
\hline February & 4,3 & $80,20 \%$ & 1,39 & 101,0 & 5,8 & 3,6 & 380 & 1 & 1,28 \\
\hline March & 6,4 & $76,80 \%$ & 2,34 & 100,9 & 6,0 & 6,2 & 353 & 4 & 2,18 \\
\hline April & 8,6 & $69,80 \%$ & 3,59 & 100,7 & 5,1 & 9,1 & 279 & 21 & 3,55 \\
\hline May & 12,7 & $64,00 \%$ & 4,57 & 100,9 & 4,7 & 13,8 & 168 & 92 & 4,11 \\
\hline June & 16,1 & $60,80 \%$ & 4,84 & 100,9 & 4,4 & 17,7 & 75 & 177 & 4,86 \\
\hline July & 18,6 & $60,20 \%$ & 4,80 & 100,9 & 4,4 & 20,4 & 25 & 261 & 4,77 \\
\hline August & 18,6 & $61,20 \%$ & 4,23 & 100,9 & 4,3 & 20,3 & 26 & 264 & 4,23 \\
\hline September & 15,5 & $66,30 \%$ & 2,86 & 100,9 & 5,0 & 16,5 & 83 & 164 & 2,85 \\
\hline October & 11,7 & $74,10 \%$ & 1,73 & 100,7 & 5,5 & 11,5 & 191 & 73 & 1,57 \\
\hline November & 7,3 & $83,20 \%$ & 0,96 & 100,7 & 5,9 & 6,4 & 318 & 11 & 0,80 \\
\hline December & 4,9 & $85,00 \%$ & 0,60 & 100,8 & 6,1 & 3,8 & 404 & 3 & 0,60 \\
\hline \multicolumn{10}{|l|}{ Annual } \\
\hline & 10,7 & $72,10 \%$ & 2,72 & 100,8 & 5,3 & 11,0 & 2728 & 1072 & \\
\hline Measured at (m) & & & & & 10,0 & 0,0 & & & \\
\hline
\end{tabular}


Table 3. The 10 locations that were presently investigated.

\begin{tabular}{|l|c|c|c|}
\hline & Latitude & Longitude & Period of observation \\
\hline Camborne & 50,21 & 5,30 & $1981-1995$ \\
\hline Crawley & 51,11 & 0,19 & $1980-1992$ \\
\hline Bracknell & 51,42 & 0,75 & $1992-1994$ \\
\hline London wcb & 51,52 & 0,11 & $1975-1995$ \\
\hline Aberporth & 52,13 & 4,55 & $1975-1995$ \\
\hline Hemsby & 52,70 & 1,69 & $1981-1995$ \\
\hline Finningley & 53,48 & 0,98 & $1982-1995$ \\
\hline Aughton & 53,54 & 2,91 & $1981-1995$ \\
\hline Aldergrove & 54,65 & $-6,24$ & $1968-1995$ \\
\hline Stornoway & 58,22 & 6,39 & $1982-1995$ \\
\hline
\end{tabular}

Table 4. High clearness index data

\begin{tabular}{|c|c|c|c|c|}
\cline { 3 - 5 } \multicolumn{1}{c|}{} & $\begin{array}{c}\text { Averaged } \\
\text { diffuse ratio }\end{array}$ & $\begin{array}{c}\text { Clearness } \\
\text { index }\end{array}$ & $\begin{array}{c}\text { Hourly } \\
\text { diffuse ratio }\end{array}$ & $\begin{array}{c}\text { Solar altitude, } \\
\text { degree }\end{array}$ \\
\hline \multirow{3}{*}{ Stornoway } & \multirow{3}{*}{0.66} & 0.65 & 0.63 & 12.3 \\
\cline { 3 - 5 } & & 0.65 & 0.57 & 20.1 \\
\cline { 3 - 5 } & \multirow{3}{*}{ Hemsby } & 0.65 & 0.79 & 4.1 \\
\hline \multirow{3}{*}{ Crawley } & \multirow{3}{*}{0.78} & 0.60 & 0.74 & 3.7 \\
\cline { 3 - 5 } & & 0.64 & 0.82 & 1.7 \\
\cline { 3 - 5 } & \multirow{3}{*}{0.75} & 0.64 & 0.77 & 3.3 \\
\hline \multirow{3}{*}{} & & 0.51 & 0.85 & 1.5 \\
\cline { 3 - 5 } & & 0.52 & 0.64 & 10.1 \\
\cline { 3 - 5 } & \multirow{3}{*}{0.69} & 0.52 & 0.78 & 2.8 \\
\cline { 3 - 5 } & & 0.55 & 0.63 & 6.9 \\
\cline { 3 - 5 } & & 0.58 & 0.71 & 4.6 \\
\cline { 3 - 5 } & & 0.59 & 0.71 & 5.9 \\
\cline { 3 - 5 } & & 0.59 & 0.73 & 4.9 \\
\hline
\end{tabular}

